\title{
ANÁLISE DA RESPOSTA NUMÉRICA DA APLICAÇÃO DE FERRAMENTAS DE OTIMIZAÇÃO DO ANSYS NA SEÇÃO TRANSVERSAL EM VIGA DE CONCRETO
}

\section{Analysis of the numerical response of the Ansys' optimization tools at the cross section in concrete beams}

\author{
Eduardo de Souza Magalhães ', Maria Cristina Vidigal de Lima ${ }^{2}$, Rodrigo Reis de Rezende Costa ${ }^{3}$
}

Recebido em 26 de novembro de 2015; recebido para revisão em 13 de fevereiro de 2016; aceito em 12 de maio de 2016; disponivel on-line em 04 de julho de 2016.

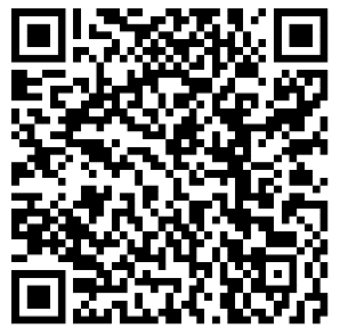

PALAVRAS CHAVE:

Otimização de seção transversal;

Modelagem numérica; Concreto armado. KEYWORDS:

Optimization of cross section;

Numerical model; Reinforced concrete.

RESUMO: O programa computacional Ansys foi utilizado neste trabalho por apresentar um eficiente menu de otimização, com métodos e ferramentas baseado em modelos matemáticos. A partir dos procedimentos iterativos e consecutivos testes executados no próprio software, o melhoramento do resultado pode ser muito expressivo na economia de materiais, de tempo de projeto e garante uma melhor eficiência estrutural de uma peça. O objetivo desta pesquisa é encontrar o melhor conjunto de soluções para o projeto de vigas biapoiadas. Os processos de otimização aplicados visam otimizar as dimensões da seção transversal, respeitando a certas restrições, a fim de se obter o menor volume de material gasto. Os resultados e análises desenvolvidas neste trabalho mostram a grande importância da otimização estrutural para o avanço da engenharia.

ABSTRACT: The Ansys computer program was used in this study to present an efficient optimization menu, with methods and tools based on mathematical models. From the iterative procedures and consecutive tests performed in the own software, the improvement of the result can be very expressive in the economy of materials, of projects time, and it ensures better structural efficiency of a piece. The objective of this research is to find the best set of solutions for the design of twice supported beams. The optimization procedures implemented aim to optimize the dimensions of the transversal section, respecting certain restrictions, in order to obtain the least amount of spent material. The results and analyzes developed in this study show the great importance of structural optimization for the progress of engineering.

* Contato com os autores:

${ }^{1}$ e-mail: esouzamagalhaes@gmail.com (E.S. Magalhães )

Graduando do curso de Engenharia Civil da Faculdade de Engenharia Civil, Universidade Federal de Uberlândia - UFU.

2e-mail: macris@ufu.br (M.C. V.de Lima )

Professora Doutora, Faculdade de Engenharia Civil da Universidade Federal de Uberlândia - UFU,

${ }^{3}$ e-mail: rodrigorrc@hotmail.com (R. R. R. Costa )

Mestrando do Programa de Pós-Graduação em Engenharia Civil (PPGEC) da Universidade Federal de Uberlândia - UFU. 


\section{INTRODUÇÃO}

Durante um longo período, executar um projeto de engenharia era tido como um trabalho árduo. Os métodos analíticos utilizados para a solução dos mesmos eram manualmente muito trabalhosos e, além disso, limitavam o número de projetos que poderiam ser resolvidos. Nos tempos mais recentes, com os grandes avanços computacionais, surgiram programas computacionais que estão sempre em constante aperfeiçoamento permitindo a simulação numérica do comportamento das estruturas. Criar um produto leve, resistente e com a melhor geometria possível é um desafio em qualquer projeto de engenharia.

A definição de otimização leva em conta um mecanismo de tomada de decisões complexas, encontrando a melhor solução de um conjunto de soluções para um problema. Esta ferramenta pode diminuir significativamente o tempo de desenvolvimento de um projeto, possibilitando o tratamento simultâneo de uma grande quantidade de variáveis e de restrições, levando a uma melhor solução, com um menor custo. Esta ferramenta é especialmente válida quando a estrutura é complexa ou existem muitas soluções para o problema (MARINHO, 2002; MACAMBIRA, 2014).

O programa computacional utilizado para o desenvolvimento deste projeto de pesquisa é o Ansys, baseado no método dos elementos finitos. Com a utilização mais adequada das ferramentas e métodos de otimização, a solução será cada vez mais precisa e eficiente. Eficiência estrutural é uma característica muito significativa para o trabalho de um projetista, e dominando a utilização de um bom software estrutural, como o Ansys, encontrar as melhores soluções para os problemas torna-se cada vez mais prático e fácil. Costa, Lima e Alva (2015) desenvolveram um estudo do problema da otimização do comportamento de sistemas estruturais pré-moldados de concreto com ligações viga-pilar deformáveis à flexão.

Neste contexto, a otimização de estruturas tornou-se uma área de grande importância devido a necessidade de se obter em tempo hábil, soluções econômicas e viáveis. Com o melhor projeto possível, o engenheiro obtém a concepção desejável do critério de funcionalidade, fabricação e solicitação (TORRES, 2001). Neste trabalho, pretende-se correlacionar a realidade prática com os procedimentos numéricos de otimização, para aplicação em casos reais. Tais procedimentos são empregados como uma ferramenta auxiliar ao projetista, para que atenda tanto os limites de aplicabilidade quanto de economia.

\section{OBJETIVOS}

O trabalho objetivou estudar os métodos e ferramentas de otimização disponíveis no programa computacional Ansys, a fim de obter melhores respostas de comportamento estrutural no problema de minimização da função objetivo, que trata das características geométricas da seção transversal de uma viga pré-moldada de concreto armado, atendendo às exigências normativas de dimensionamento.

\section{FUNDAMENTOS DE OTIMIZAÇÃO}

Otimização compreende o processo que busca minimizar ou maximizar uma função pela escolha sistemática de valores de variáveis, dentro de um conjunto viável. Por convenção, a forma padrão de um problema de otimização é definida em termos de minimização. Assim, para uma função $F$ chamada de função objetivo, busca-se uma solução viável que a minimize, sendo chamada de solução ótima. Problemas gerais de otimização não linear com restrições, que são os mais frequentes em engenharia, podem ser desenvolvidos minimizando a Equação 1, sujeita às Equações 2 e 3 (KIM, 2003).

$$
\mathrm{F}=\mathrm{F}(\mathrm{x})
$$

Sujeita a:

$$
\begin{aligned}
& \mathrm{g}_{\mathrm{i}}(\mathrm{x}) \leq \overline{\mathrm{g}_{\mathrm{i}}} \quad\left(\mathrm{i}=1,2,3, \ldots, \mathrm{m}_{1}\right) \quad \text { Eq.[2] } \\
& \mathrm{w}_{\mathrm{i}} \leq \mathrm{w}_{\mathrm{i}}(\mathrm{x}) \leq \overline{\mathrm{w}_{\mathrm{i}}} \quad\left(\mathrm{i}=1,2,3, \ldots, \mathrm{m}_{2}\right) \quad \text { Eq.[3] } \\
& \text { Algumas definições são muito }
\end{aligned}
$$


como:

- Função Objetivo: é a função que se deseja otimizar. Nela podem estar associadas uma ou mais variáveis;

- Variáveis de Projeto: são as variáveis independentes que aparecem na função objetivo e se alteram durante o processo de otimização. Correspondem, em número, ao grau de liberdade do sistema;

- Restrições de Projeto: descrevem situações não desejadas ao projeto, são os limites impostos ao sistema ou determinados pela natureza do comportamento do mesmo. A decisão depende destas restrições;

- Região de Busca: é a região do espaço delimitada pelas restrições e abrange todas as soluções possíveis do problema. O ótimo da função objetivo se encontra no interior ou nas fronteiras desta região;

- Ponto Ótimo: é o ponto, caracterizado pelo vetor $X^{*}=[X 1, X 2, \ldots, X n]$, compreendido pelas variáveis de projeto que extremizam a função objetivo e satisfazem as restrições. O valor ótimo é o valor da função objetivo no ponto ótimo, $F\left(X^{*}\right)$. Solução ótima é o par formado pelo ponto ótimo e o valor ótimo da função objetivo, $\left[X^{*}, F\left(X^{*}\right)\right]$.

Devido ao caráter multimodal da função objetivo, podem existir pontos de soluções locais. No procedimento da otimização deve-se evitar a convergência da função a estes pontos, buscando a solução global. Nas aplicações, raramente pode-se garantir que a solução ótima absoluta será encontrada, para isso a solução ótima, a função objetivo e o ponto de partida devem ser favoráveis na busca. A melhor forma de resolver um problema de otimização é iniciando o procedimento com vários pontos de partida e, se os resultados levarem essencialmente à mesma solução final, pode-se assegurar que, com relativa segurança, esta solução é o ótimo verdadeiro. Porém, em muitos casos, uma solução ótima local pode ser muito eficiente, pois em muitas aplicações encontrar o ótimo global não é necessário ou é praticamente impossível. Pode ser mais desejável encontrar uma boa solução em menor espaço de tempo, do que a melhor possível, em um processo muito demorado (MARINHO, 2002).

\subsection{MÉTODOS DE OTIMIZAÇÃO}

Existem várias classificações para os métodos de otimização. Uma classificação muito utilizada refere-se à natureza determinística ou não determinística dos algoritmos de busca. Neste caso, os métodos podem ser classificados como métodos determinísticos ou métodos estocásticos.

Para problemas de maior complexidade, onde a otimização não é possível com os métodos determinísticos ou simplesmente não é eficiente o suficiente para gerar soluções em um tempo razoável, são utilizados os métodos estocásticos, também conhecidos por heurísticos. No trabalho foram empregados apenas métodos determinísticos por se tratarem de ferramentas numéricas disponíveis no programa computacional Ansys.

\subsubsection{Métodos determinísticos}

Os métodos determinísticos são constituídos por algoritmos que geralmente fazem uso direto do cálculo de derivadas ou necessitam de algum tipo de informação do gradiente, seja procurando o ponto em que ele se anula, ou usando a direção para o qual ele aponta (ÁVILA, 2002).

O problema é tratado de forma iterativa, requer informações e condições do problema a ser resolvido, como região de busca bem definida, convexidade do problema e suavidade da função objetivo. Um algoritmo de otimização determinístico segue basicamente três fases, que são o cálculo da direção de busca, o cálculo do passo de busca e, por último, a verificação da convergência. Existem diferentes formas de classificar os métodos determinísticos, uma delas é quanto à utilização de derivadas:

- Métodos de ordem zero: utilizam apenas os valores das funções, sem a utilização de derivadas da função objetivo. São também conhecidos como métodos diretos, normalmente confiáveis e de fácil aplicação computacional. Eles operam através de um procedimento simples de comparação de valores, porém isto o torna lento, pois 
necessitam de um alto número de avaliações da função objetivo. Apresentam eficiência e robustez quando o número de parâmetros não é muito elevado;

- Métodos de primeira ordem: uma segunda categoria dos métodos de otimização, de maior dificuldade, mas geralmente muito eficientes, é o uso da informação do gradiente. Utilizam derivadas de primeira ordem da função objetivo em função das variáveis de projeto. Usando o gradiente de $F(X)$, limita-se a busca a uma dada direção, evitando a busca randômica em todo o espaço, o que pode levar a soluções locais. Possuem maior eficiência numérica em relação aos métodos de ordem zero, porém são mais difíceis de implementar;

- Métodos de segunda ordem: Seguindo o raciocínio, estes métodos utilizam derivadas de primeira e segunda ordem da função objetivo em função das variáveis de projeto. São considerados métodos rápidos por apresentarem convergência quadrada. No entanto, muitas vezes não são viáveis, lembrando que o cálculo da derivada de segunda ordem pode ser muito trabalhoso. Este procedimento geralmente tem um alto custo computacional e é pouco utilizado.

No entanto, vale lembrar que a escolha do método adequado depende de uma análise prévia do problema, da precisão desejada, de bom senso e da experiência do usuário, já que a maior complexidade de uma técnica não lhe assegura necessariamente maior eficiência nas aplicações práticas (TORRES, 2001).

\subsection{OTIMIZAÇÃO ESTRUTURAL VIA ANSYS}

O Ansys é um programa computacional com imensa funcionalidade em problemas de engenharia. Ele utiliza do Método de Elementos Finitos para promover inúmeros tipos de análises estruturais que seriam difíceis ou até impossíveis através de procedimentos analíticos tradicionais da matemática. Para este caso, recorre-se frequentemente à utilização de métodos aproximados e satisfatórios de análises.

A solução de um problema estrutural por meio do Método dos Elementos Finitos (MEF) é realizada com a discretização da estrutura contínua, isto é, dividir a estrutura complexa em várias subestruturas de formas geométricas e soluções simples. Cada subestrutura da discretização é chamada de elemento, e são conectados pelos nós em seus vértices, com coordenadas locais que são definidas, e a união desse conjunto é chamadas de malha de elementos finitos (SORIANO, 2003).

A partir de uma função aproximada, denominada função de interpolação, é feita a solução de cada elemento isoladamente, em função dos valores da solução nos nós, que são as incógnitas do problema. Esta função mantém a continuidade da solução já que há igualdade das incógnitas nos nós entre as fronteiras dos elementos. Com a sequência dos elementos solucionados chega-se à solução global da malha. Geralmente, quanto maior o refinamento da malha, isto é, quanto menores forem os elementos, mais precisa se torna a análise. Por isso, em pontos críticos onde a estrutura é mais solicitada, recomenda-se um maior refinamento (HUEBNER e THORNTON 1982; COOK, MALKUS e PLESHA 1989). A modelagem estrutural no programa Ansys é dividida, basicamente, em três etapas:

- Pré-processador: onde é feita a entrada dos dados para a resolução do problema, envolvendo o tipo de elemento (viga, placa, sólido, etc.), as propriedades mecânicas do material a serem utilizadas (módulo de elasticidade, densidade, etc.), propriedades geométricas (espessura, área, inércia da seção transversal, etc.), geração da malha (nós e elementos), aplicação dos esforços atuantes na estrutura (forças estáticas, temperaturas, etc.) e condições de contorno (condições de apoio);

- Solução: entrada do tipo de cálculo a ser realizado (estático, dinâmico, flambagem, etc.);

- Pós-processador: análise dos resultados (listar, plotar, exportar e visualizar).

Finalmente, após processada a estrutura, tem-se disponível a possibilidade de aplicar a ferramenta de otimização. A solução ótima é encontrada automaticamente através do 
procedimento iterativo, sendo realizadas as iterações até a possível convergência da função (ANSYS, 2009). A cada iteração, novos valores para a função objetivo são encontrados e novamente avaliados. Se a convergência do processo é encontrada, a partir de critérios definidos, a otimização está realizada com sucesso.

Após a conclusão do processo de otimização, devem ser avaliados os resultados a fim de saber se os mesmos são satisfatórios. O programa pode simplesmente ter parado a otimização sem convergir por ter chegado ao máximo número de ciclos pré-estabelecido, ou por ter encontrado uma vasta sequência de projetos inviáveis. O número máximo de ciclos ou também consecutivo de projetos inviáveis podem ser escolhidos manualmente pelo usuário na escolha e aplicação do método ou ferramenta de otimização.

Quando se inicia o procedimento de otimização com um projeto inviável, pode-se não alcançar a convergência. Nesta situação, sugere-se a reinicialização a partir de um novo projeto inicial. (MARINHO, 2002). Os dois métodos de otimização disponíveis no Ansys são:

- Aproximação por Subproblema: é um método de ordem zero avançado que usa curvas de ajuste para cada uma das variáveis dependentes;

- Primeira Ordem: é um método de primeira ordem bastante eficaz quando orientado na direção correta, para a solução global, porém com um maior número de variáveis o esforço computacional provocado pode ser uma consequência.

Além destes dois métodos de otimização há também o "Ferramenta de Projeto Oferecida pelo Usuário", onde há como implementar um algoritmo de otimização externo, através da linguagem de programação APDL (Ansys Parametric Design Language).

A utilização das ferramentas de otimização do Ansys abre um leque ainda maior para a busca da solução ótima. Estas ferramentas permitem que a qualidade dos resultados do procedimento seja ainda mais confiável, sendo utilizadas em conjunto com os métodos de otimização na obtenção do projeto final. As ferramentas disponíveis são as seguintes (ANSYS, 2009; MARINHO, 2002; COSTA, 2015):

- Única Iteração: esta ferramenta executa uma única iteração a cada vez em que é executada. É uma vantagem ao fazer um estudo onde analisa-se o resultado de cada iteração separadamente, fixando, para projetos diferentes, valores das variáveis antes de cada ciclo;

- Geração de Projeto Aleatória/Randômica: são executadas diversas iterações, com valores aleatórios das Variáveis de Projeto a cada iteração. Um número máximo de iterações e um número máximo de conjuntos viáveis podem ser especificados manualmente pelo usuário. Esta ferramenta tem grande utilidade para estudar o espaço de projeto global, descobrindo em que região se encontra o legítimo ótimo global e, assim estabelecer possíveis conjuntos de projeto para análises de otimização subsequentes. Esta ferramenta é muito utilizada como precursor do Método de Aproximação por Subproblema, avaliando regiões aleatórias do espaço e selecionando o melhor caminho para os fins designados pelas variáveis e função objetivo;

- Avaliação Fatorial: usada para gerar conjuntos de projeto com todas as combinações extremas de valores das variáveis de projeto. Esta técnica usa uma análise completa fatorial e fracionária, computando a principal iteração efetuada para a função objetivo e as variáveis de estado. Temse duas opções de escolha na execução da Avaliação Fatorial, optando por "Avaliação Completa" o programa executa $2^{n}$ iterações, onde $\mathrm{n}$ é o número de variáveis de projeto. Já a opção "Avaliação Fracionada" gera um número de iterações correspondente a uma fração do número de iterações obtidas com a "Avaliação Completa";

- Avaliação de Gradiente: para um conjunto de projeto determinado pelo projetista, esta ferramenta calcula os gradientes da função objetivo e das variáveis de estado em função das variáveis de projeto. Usando esta 
ferramenta, pode-se ter ideia das sensibilidades de projeto locais, comparando as alterações de valores em relação ao projeto inicial. Isto, pois essa ferramenta tende fortemente a mudar a direção de busca em sentido a soluções locais quando se aproxima a estas, convergindo erroneamente. O número de ciclos realizados para esta ferramenta é igual ao número de Variáveis de Projeto;

- Geração de Varredura: a partir de um conjunto de projeto definido, esta ferramenta gera várias sucessões de conjuntos de projeto. Os novos conjuntos de projeto são criados de forma que, divide-se o espaço de busca em tamanhos iguais por um número especificado pelo usuário (NSPS). Especificamente, é modificado o valor de apenas uma Variável de Projeto por vez usando os incrementos uniformes do início ao fim do espaço de busca. O valor das outras Variáveis de Projeto é mantido constante enquanto a primeira testa todos os valores e, consecutivamente, repetese o mesmo processo para as outras variáveis. São geradas exatamente $n \times$ NSPS iterações, onde " $n$ " é o número de Variáveis de Projeto e "NSPS" é o número de pontos de avaliação por varredura.

A escolha do método de otimização e das ferramentas disponíveis para o desenvolvimento da otimização deve levar em conta suas características e limitações. Assim, a ferramenta de Única Iteração é descartada inicialmente pelo fato de realizar apenas uma iteração a cada execução, já que o objetivo é obter o projeto ótimo no menor intervalo de tempo possível.

As ferramentas de Avaliação Fatorial e Avaliação de Gradiente são limitadas ao número de variáveis de projeto. Como o número de variáveis de projeto para o problema proposto é pequeno, apenas duas (altura e largura da seção transversal da viga), ambas as ferramentas serão pouco eficientes e bastante limitadas quanto ao número de iterações na busca da solução ótima. Portanto, as ferramentas a serem analisadas em conjunto com os dois métodos de otimização (Primeira Ordem e Aproximação por Subproblema) são
Geração de Projeto Aleatória/Randômica e Geração de Varredura.

\section{OTIMIZAÇÃO DAS DIMENSÕES DA SEÇÃO TRANSVERSAL DE UMA VIGA DE CONCRETO ARMADO DIMENSIONADA NO DOMÍNIO 3}

A peça estrutural aqui analisada trata-se de uma viga de concreto armado de seção retangular, a qual será dimensionada para o Estado Limite Último (ELU) e feita a verificação da deformação limite pelo Estado Limite de Serviço (ELS). O tipo de elemento utilizado no Ansys foi o BEAM3, que se refere ao elemento bidimensional de viga. Algumas propriedades físicas e geométricas iniciais da estrutura em análise são indicadas como: comprimento $(L)=4 \mathrm{~m}$; altura inicial $(H)=50 \mathrm{~cm}$; largura inicial $(W)=40 \mathrm{~cm}$ e tensão resistente característica do concreto $\left(f_{c k}\right)=30 \mathrm{MPa}$.

O problema trata-se de uma viga biapoiada, sujeita ao carregamento $(q)$ que soma o peso próprio às outras cargas permanentes (80 kN/m), Equação 4.

$$
q=0,8+(b \times h) \times \gamma
$$

Em que:

q-carregamento, em $\mathrm{kN} / \mathrm{cm}$;

b - largura da viga, em cm;

$\mathrm{h}$ - altura da viga, em $\mathrm{cm}$;

$\gamma$ - peso específico do concreto, igual a $25 \times 10^{-6}$ $\mathrm{kN} / \mathrm{cm}^{3}$ (NBR 6118, ABNT, 2014).

O aço a ser utilizado para as barras da armadura longitudinal é de alta resistência, CA-50, com diâmetro pré-fixado de $2 \mathrm{~cm}$. A viga de concreto armado pertence a uma edificação do tipo 2 , onde as cargas acidentais não superam $5 \mathrm{kN} / \mathrm{m}^{2}$, conforme recomendado pela norma ABNT NBR 8681:2003, e encontra-se em ambiente urbano. Para a viga de concreto armado será analisado apenas o caso de armaduras simples, excluindo a utilização de armadura dupla.

O objetivo é encontrar a armação simples que combinada às dimensões otimizadas da seção transversal da viga resultem no menor volume de material utilizado, estabelecido que o dimensionamento seja desenvolvido para o domínio 3. Neste domínio, ocorre flexão simples ou 
composta com a deformação última do concreto $\left(\varepsilon_{c, u}\right)$ de $3,5 \%$ e deformação do aço $\left(\varepsilon_{s}\right)$ menor que $10 \%$ e maior que a deformação de escoamento $\left(\varepsilon_{y d}\right)$. No caso do aço CA50, $\varepsilon_{y d}=2,070 \%$ o. O domínio 3 é tido como o mais econômico, pois tanto o aço quanto o concreto estão solicitados ao limite de suas capacidades.

Não são realizados cálculos de dimensionamento das armaduras transversais resistentes às tensões cisalhantes, mas para efeitos de consideração nos cobrimentos das armaduras são definidos diâmetros de $5 \mathrm{~mm}$ para os estribos.

Para o dimensionamento utiliza-se o

Método Semi-probabilístico, definido pela Norma NBR 8681 (ABNT, 2003). Neste método majoram-se as ações características de modo que a probabilidade de ocorrer ação superior não ultrapassa $5 \%$, o que resulta na ação de cálculo $\left(F_{d}\right)$, e também minoram-se as resistências características dos materiais de modo que a probabilidade de ocorrência de valor inferior ao minorado não ultrapasse $5 \%$, encontrando a resistência de cálculo $\left(f_{d}\right)$. Logo, há segurança no dimensionamento se a solicitação de cálculo não superar a capacidade resistente de cálculo.

Para a viga de concreto armado aqui analisada todo o carregamento é considerado como ação permanente, isto para efeito de simplificação do cálculo onde não seja necessário majorar com coeficientes diferentes as cargas variáveis.

A distribuição de tensões de compressão no concreto é feita de acordo com o diagrama parábola-retângulo definido no índice 8.2.10.1 da norma NBR 6118 (ABNT, 2014), com tensão de pico de $0,85 f_{c d}$. Este pode ser substituído por um diagrama retangular com profundidade $y=\lambda x$, onde $\lambda=0,8$ para o caso de $f_{c k} \leq 50 \mathrm{MPa}$, definido no índice 17.2.2 desta mesma norma. A tensão nas armaduras deve ser obtida a partir do diagrama tensão-deformação definidos nos índices $8.3 .6 \mathrm{e}$ 8.4.5 para o aço. Para as vigas, a maior ductilidade corresponde à linha neutra mais próxima da borda comprimida, definida no item 14.6.4.3 para $\mathrm{f}_{\mathrm{ck}} \leq 50 \mathrm{MPa}$ como $x / d \leq 0,45$.
A Figura 1 mostra o esquema da viga estudada quando sujeita a flexão simples, onde "Rcc" é a resistência do concreto na compressão, "Rst" é a resistência do aço na tração, "d" é a altura útil, " $x$ " é a distância da linha neutra até a borda comprimida e " $h$ " é a altura da seção transversal.

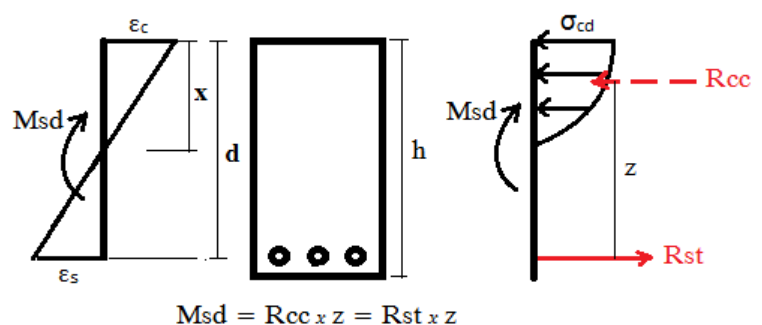

FIGURA 1: Esquema representativo das resistências na flexão simples.

FONTE: Autoria própria.

Tratando-se de uma edificação do tipo 2, todas as cargas características permanentes são majoradas pelo coeficiente de $\gamma=1,4$, de acordo com o índice 5.1.4 da norma NBR 8681 (ABNT, 2003), e assim é encontrado o valor de cálculo do momento (Msd).

O cobrimento nominal da viga é definido a partir da Tabela 7.2 da norma NBR 6118 (ABNT, 2014) de acordo com o ambiente em que a peça se encontra. Pode-se fazer a redução no cobrimento de $5 \mathrm{~mm}$ caso o $f_{c k}$ utilizado seja superior ao $f_{c k, m i n}$ dado na tabela. Desta forma, para o ambiente urbano, CAA II, o cobrimento para vigas é de $3 \mathrm{~cm}$, com o $\mathrm{f}_{\mathrm{ck} \text {,mín }}$ de $25 \mathrm{MPa}$. Porém, como o $f_{c k}$ do concreto para a viga em questão é de $30 \mathrm{MPa}$, pode-se reduzir o cobrimento para $2,5 \mathrm{~cm}$.

A altura útil da viga " $d$ " compreende a distância entre o eixo das barras longitudinais e a borda superior da seção transversal da viga, borda comprimida. Conhecendo a altura da peça, o cobrimento, o diâmetro dos estribos e o diâmetro das barras longitudinais, é calculada a altura útil da viga (Equação 5).

$$
\mathrm{d}=\mathrm{h}-\mathrm{c}-\emptyset_{\mathrm{t}}-\frac{\emptyset}{2}
$$

Em que:

$\mathrm{d}$ - altura útil da viga, em $\mathrm{cm}$;

$\mathrm{h}$ - altura da viga, em $\mathrm{cm}$;

c - cobrimento na viga, igual a $2,5 \mathrm{~cm}$;

$\emptyset_{\mathrm{t}}$ - diâmetro dos estribos, iguais a $0,5 \mathrm{~cm}$;

$\varnothing$-diâmetro das barras longitudinais, de $2 \mathrm{~cm}$. 


\subsection{DIMENSIONAMENTO DA VIGA DE CONCRETO ARMADO}

Para o dimensionamento utiliza-se a combinação última normal de ações, obrigatória, no Estado Limite Último (ELU), dado pela Equação 6.

$$
\begin{aligned}
& \mathrm{F}_{\mathrm{d}}=\sum_{\mathrm{i}=1}^{\mathrm{n}} \gamma_{\mathrm{gi}} \times \mathrm{F}_{\mathrm{gi}, \mathrm{k}}+\gamma_{\mathrm{q} 1} \times \mathrm{F}_{\mathrm{q} 1, \mathrm{k}}+ \\
& \sum_{\mathrm{j}=2}^{\mathrm{n}} \gamma_{\mathrm{qj}} \times \varphi_{0 \mathrm{j}} \times \mathrm{F}_{\mathrm{qj}, \mathrm{k}}
\end{aligned}
$$

\section{Em que:}

$\mathrm{F}_{\mathrm{d}}$ - valor da ação de cálculo;

$\mathrm{F}_{\mathrm{gi}, \mathrm{k}}$ - valor característico da ação permanente;

$\mathrm{F}_{\mathrm{qj}, \mathrm{k}}$ - valor característico da ação variável;

$\mathrm{F}_{\mathrm{q} 1, \mathrm{k}}$ - ação variável principal;

$\gamma$-coeficientes de majoração.

Para a determinação da armadura efetiva a ser locada na seção da viga, uma série de cálculos sucessivos são necessários. Primeiramente é encontrado o valor do coeficiente " $k$ ", pela Equação 7, a partir de valores já conhecidos.

$$
\mathrm{k}=\frac{\mathrm{d}}{\sqrt{\frac{\mathrm{Msd}}{\mathrm{b} \times \mathrm{fcd}}}}
$$

Em que:

k - coeficiente a ser encontrado para o dimensionamento, adimensional;

$\mathrm{d}$ - altura útil, em $\mathrm{cm}$;

Msd - valor de cálculo do momento, em kN.cm;

b - largura da seção transversal, em cm;

fcd - valor de cálculo da tensão do concreto, correspondente a $\frac{\mathrm{fck}}{\gamma_{\mathrm{d}}}$, onde $\gamma_{\mathrm{d}}=1,4$ e fcd é dado em $\mathrm{kN} / \mathrm{cm}^{2}$.

Limitando o dimensionamento com a utilização apenas de armadura simples, o valor de "k" é limitado com o mínimo de 1,993. Também deseja-se que a estrutura seja dimensionada no domínio 3, e para isso também é definido um limite superior, 2,507, que corresponde ao valor máximo de " $k$ " este domínio atinge. Portanto, tem-se que $1,993 \leq k \leq 2,507$, com uma tolerância de 0,01, para efeitos de otimização. Portanto, o coeficiente é uma variável de estado, que deve obedecer as restrições.

Uma vez obtido o valor de "k", pode-se determinar o valor do coeficiente $\alpha$ para o cálculo da área de aço necessária na seção transversal da viga sujeita ao maior momento e, que depende do tipo de aço utilizado. O valor de $\alpha$ para o domínio 3 é aproximado pela Equação 10 e, depende do parâmetro " $\xi$ " que é a relação entre a distância da linha neutra na seção transversal até borda comprimida $(x)$ e a altura útil $(d)$. A sequência de cálculo para a obtenção do valor de " $\alpha$ " é mostrado com as Equações 8, 9 e 10.

$$
\mu=\frac{1}{\mathrm{k}^{2}}
$$

Em que:

k - coeficiente adimensional anteriormente encontrado.

Entretanto, tem-se ainda que $\mu=0,68 \times$ $\xi \times(1-0,4 \times \xi)$. Assim, a partir desta igualdade e com o valor de " $\mu$ " encontrado na Equação 8, o valor de "§" pode ser encontrado pela Equação 9. Por fim, encontra-se o valor desejado para " $\alpha$ ", através da Equação 10.

$$
\begin{aligned}
& \xi=\frac{x}{d}=\frac{1-\sqrt{1-2,35394 \times \mu}}{0,8} \\
& \alpha=\frac{\sigma_{\mathrm{sd}}}{\mathrm{k}^{2} \times 0,68 \times \xi}, \\
& \text { em que } \sigma_{\mathrm{sd}}=\text { fyd }=\frac{\text { fyk }}{\gamma_{\mathrm{s}}}
\end{aligned}
$$

Em que:

$\sigma_{\text {sd }}$ - tensão de escoamento de cálculo do aço, em $\mathrm{kN} / \mathrm{cm}^{2}$;

k - coeficiente adimensional para o dimensionamento;

$\xi$ - razão entre a distância da linha neutra da borda comprimida e a altura útil;

fyd - tensão máxima de escoamento de cálculo do aço, em kN/ $\mathrm{cm}^{2}$;

fyk - tensão de escoamento característica do aço, $50 \mathrm{kN} / \mathrm{cm}^{2}$ para o CA50;

$\gamma_{\mathrm{s}}$ - coeficiente de minoração, igual a 1,15 para o ELU.

Conclui-se o dimensionamento com a área de aço necessária (As,calc) e definindo a área de aço efetivamente utilizada (As,ef). Para o cálculo da área de aço necessária tem-se a Equação 11.

$$
\text { As, calc }=\frac{\text { Msd }}{\alpha \times d}
$$




\section{Em que:}

As,calc - área de aço necessária, em $\mathrm{cm}^{2}$;

Msd - valor de cálculo do momento atuante, em $\mathrm{kNcm}$;

$\mathrm{d}$ - altura útil, em $\mathrm{cm}$.

Com o valor da área de aço necessária pode-se determinar o número de barras ( $n$ ) a ser utilizado na armadura efetiva, através da Equação 12.

$$
\mathrm{n}(\text { valor inteiro })=\frac{\text { As, calc }}{A s_{\varnothing=20 \mathrm{~mm}}}+1 \quad \text { Eq.[12] }
$$

\section{Em que:}

$\mathrm{n}$ - número de barras necessários;

As,calc - área de aço necessária, em $\mathrm{cm}^{2}$;

$\mathrm{As}_{\emptyset=20 \mathrm{~mm}}$ - área da seção transversal de apenas uma barra longitudinal, em $\mathrm{cm}^{2}$.

Por último, calcula-se a área de aço efetiva conforme a Equação 13.

$$
\text { As, ef }=n \times A s_{\varnothing=20 m m}
$$

\section{Em que:}

As,ef- área de aço efetiva, em $\mathrm{cm}^{2}$;

$\mathrm{n}$ - número de barras necessários;

$A s_{\emptyset=20 \mathrm{~mm}}$ - área da seção transversal de apenas uma barra longitudinal, em $\mathrm{cm}^{2}$.

O espaçamento mínimo adotado entre as barras é de $2 \mathrm{~cm}$, igual ao diâmetro da barra, não sendo influenciada pela espessura do mangote do vibrador, já que são barras próximas à face inferior da viga. O espaçamento pode ser verificado a partir da Equação 14.

$$
\mathrm{s} \text { (arredondado "para baixo") }=\frac{\mathrm{b}}{\mathrm{n}} \quad \text { Eq. [14] }
$$

\section{Em que:}

s - espaçamento entre barras longitudinais, em cm;

b - largura da viga, em cm;

n - número de barras longitudinais.

Uma solução ótima, para efeitos de minimização do volume, consiste em calcular a dimensão mínima para a largura da seção da viga para uma dada quantidade de barras (Equação 15).

$$
\begin{aligned}
\mathrm{b}_{\text {mín }}=2 \times \mathrm{c}+ & 2 \times \emptyset_{\mathrm{t}}+\mathrm{n} \times \varnothing \\
+ & (\mathrm{n}-1) \times \mathrm{s}
\end{aligned}
$$

Em que:

$$
\text { b mín - largura mínima, em cm; }
$$

c - cobrimento, igual a 3,5 cm;

$\emptyset_{\mathrm{t}}$ - diâmetro dos estribos, igual a $0,5 \mathrm{~cm}$;

$\mathrm{n}$ - número de barras longitudinais;

$\varnothing$ - diâmetro das barras longitudinais, adotado de $2 \mathrm{~cm}$;

s - espaçamento entre barras longitudinais, adotado de $2 \mathrm{~cm}$.

A área de aço efetiva calculada (As,ef) ainda deve atender aos parâmetros de área de armadura máxima e área de armadura mínima. A armadura máxima corresponde a $4 \%$ da área de armadura de concreto, isto é, As, máx $=0,04 \times$ b $\times$ h. Já para a armadura mínima deve-se obedecer a dois critérios. $O$ primeiro critério define que como limite para armadura mínima a taxa de $0,15 \%$ da área de concreto, isto é, As, mín = $0,0015 \times b \times h$. O segundo critério é definido de forma que se calcula o momento mínimo solicitante “Md,mín” a partir da Equação 16.

$$
\text { Md, mín }=0,8 \times \frac{\text { Ic }}{y t} \times \text { fctk }_{\text {sup }}
$$

\section{Em que:}

Md,mín - momento solicitante mínimo, em kNcm; Ic - momento de inercia da seção de concreto, em $\mathrm{cm}^{4}$;

yt - distância da linha neutra até a borda tracionada, (h-x), aqui aproximada por $h / 2$;

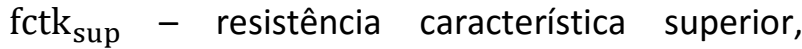
$\mathrm{kN} / \mathrm{cm}^{2}$, onde $\mathrm{fctk}_{\text {sup }}=1,3 \times 0,3 \times \frac{\mathrm{fck}(\mathrm{MPa})^{\frac{2}{3}}}{10}$.

Encontrado o valor do "Md,mín", o valor de "As,mín" a ser obedecido é determinado pela mesma sequência de cálculo já aqui utilizada para o cálculo de "As,calc".

\subsection{VERIFICAÇÃO DA DEFORMAÇÃO}

O estado limite de deformação excessiva (ELS-DEF) é de verificação obrigatória, assim como o estado limite de fissura inaceitável (ELS-W), porém o segundo não é aqui analisado. Combinações de ações quase permanentes são dadas pela Equação 17.

$$
\mathrm{F}_{\mathrm{d}, \mathrm{serv}}=\sum_{\mathrm{i}=1}^{\mathrm{n}} \mathrm{F}_{\mathrm{gi}, \mathrm{k}}+\sum_{\mathrm{j}=1}^{\mathrm{n}} \varphi_{2} \times \mathrm{F}_{\mathrm{qj}, \mathrm{k}}
$$




\section{Em que:}

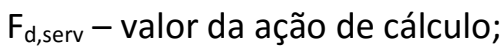

$\mathrm{F}_{\mathrm{gi}, \mathrm{k}}$ - valor característico da ação permanente;

$\mathrm{F}_{\mathrm{qj}, \mathrm{k}}$ - valor característico da ação variável;

$\varphi_{2}$ - coeficiente de minoração.

Para a verificação da flecha faz-se uma comparação entre o momento atuante em serviço "Ma" com o momento de fissuração "Mr" dado pela Equação 18.

$$
\mathrm{Mr}=\alpha \times \frac{\mathrm{Ic}}{\mathrm{yt}} \times \mathrm{fct}, \mathrm{m}
$$

Em que:

$\alpha$ - coeficiente de forma e estado, para seção retangular tem valor de 1,5 ;

Ic - momento de inércia considerando toda a área de concreto e as armaduras, em $\mathrm{cm}^{4}$;

yt - distância da linha neutra até a borda tracionada, considerando toda a área de concreto, em cm;

$\mathrm{fct}, \mathrm{m}$ - resistência média, $\mathrm{kN} / \mathrm{cm}^{2}$, onde fct, $\mathrm{m}=$ $0,3 \times \frac{\mathrm{fck}(\mathrm{MPa})^{\frac{2}{3}}}{10}$.

A norma NBR 6118 (ABNT, 2014) define o valor de $\alpha_{\mathrm{e}}$, sendo a relação entre o módulo de elasticidade do aço e o módulo de elasticidade secante do concreto, isto é, $\alpha_{\mathrm{e}}=\mathrm{Es} / \mathrm{Ecs}$. O módulo de elasticidade do aço (Es) é igual a $21000 \mathrm{MPa}$. O módulo de elasticidade secante do concreto (Ecs) é determinado pela Equação 19.

$$
\mathrm{Ecs}=\alpha_{\mathrm{i}} \times \mathrm{Eci}
$$

Em que:

Ecs - módulo de elasticidade secante, em $\mathrm{kN} / \mathrm{cm}^{2}$; $\alpha_{i}$ - coeficiente de minoração, onde $\alpha_{i}=0,8+$ $0,2 \times \frac{\text { fck }}{80}$;

Eci - módulo de elasticidade inicial, em $\mathrm{KN} / \mathrm{cm}^{2}$, onde Eci $=\alpha_{E} \times 5600 \times \sqrt{f c k}$, em que $\alpha_{E}=1,2$ é o coeficiente para o agregado de basalto.

O coeficiente $\alpha_{\mathrm{e}}$ é utilizado no cálculo da localização da linha neutra e, posteriormente, para a inércia como um fator de equivalência para o aço em relação ao concreto. Assim, representa quantas vezes mais a área do aço interfere para a inércia da viga em comparação à área de concreto.

Os valores das distâncias da linha neutra até a borda comprimida são encontrados a partir do equilíbrio, igualando o momento estático na região comprimida com o momento estático na região tracionada. Em geral, parte da estrutura encontrase no estádio I e sua inércia é Ic, a qual é determinada considerando a toda a área de concreto, e parte da estrutura encontra-se no estádio $\|$, com inércia $\mathrm{I}_{\|}$, determinada desconsiderando a área de concreto da região fissurada (tracionada).

- Se o momento atuante $(\mathrm{Ma}) \geq$ momento de fissuração (Mr) $\rightarrow$ estádio II e inércia $I_{\|}$.

- Se o momento atuante (Ma) < momento de fissuração (Mr) $\rightarrow$ estádio I e inércia Ic.

A norma NBR 6118 (ABNT, 2014) fixa no capítulo 17 um valor de inércia equivalente a considerar, a partir de Ic e $I_{\|}$, dado pela Equação 20.

$$
\text { Ieq }=\mathrm{Ic} \times\left(\frac{\mathrm{Mr}}{\mathrm{Ma}}\right)^{3}+\mathrm{I}_{\mathrm{II}} \times\left[1-\left(\frac{\mathrm{Mr}}{\mathrm{Ma}}\right)^{3}\right]
$$

Em que:

leq - momento de inércia equivalente, a partir de Ic e $I_{\|}$, em cm${ }^{4}$;

Ic - momento de inércia da seção transversal considerando toda a área de concreto, $\mathrm{em} \mathrm{cm}^{4}$; $\mathrm{Mr}$ - momento de fissuração, em kNcm; $\mathrm{Ma}$ - momento atuante em serviço, em $\mathrm{kNcm}$; $I_{\text {II }}$ - momento de inércia da seção transversal desconsiderando a área de concreto fissurada, $\mathrm{em} \mathrm{cm}^{4}$.

No cálculo da flecha total da viga, tem-se somente a parcela da carga permanente $f_{\text {total }}=f_{\text {permanente }}=f_{g}$, já que foi desconsiderado cargas acidentais para simplificação. A sequência de cálculos para a determinação da flecha total encontra-se das Equações 21 a 23 . O valor limite para a flecha é dado pela Equação 24.

$$
\begin{gathered}
\mathrm{f}_{\mathrm{g}}=\mathrm{f}_{\mathrm{g}, 0} \times\left(1+\alpha_{\mathrm{f}}\right) \\
\alpha_{\mathrm{f}}=\frac{\Delta \xi}{1+50 \rho^{\prime}}=\frac{\xi_{\mathrm{t}}-\xi_{\mathrm{t} 0}}{1+50 \rho^{\prime}} \\
\therefore \alpha_{\mathrm{f}}=1,3373 \quad \mathrm{f}_{\text {total }}=\mathrm{f}_{\mathrm{g}, 0} \times 2,3373 \\
\mathrm{f}_{\text {lim }}=\frac{1}{250}
\end{gathered}
$$




\section{Em que:}

Para $\mathrm{t}>70$ meses $\rightarrow \xi_{\mathrm{t}}=2$;

Para $\mathrm{t} \leq 70$ meses $\rightarrow \xi_{\mathrm{t}}=0,68 \times(0,996)^{\mathrm{t}} \times \mathrm{t}^{0,32}$, para $\mathrm{t}_{0}=28$ dias $\rightarrow \xi_{\mathrm{t} 0}=0,6627$;

$\rho^{\prime}$ - referente a taxa de armadura de compressão, inexistente no caso;

$\mathrm{f}_{\mathrm{g}, 0}$ - flecha inicial devido à carga permanente, onde $\mathrm{f}_{\mathrm{g}, 0}=\frac{5 \times \mathrm{q} \times \mathrm{l}^{4}}{384 \times \mathrm{E} \times \mathrm{I}_{\text {vão }}}=\frac{5 \times \mathrm{q} \times \mathrm{l}^{4}}{384 \times \mathrm{Ecs} \times \text { Ieq }_{\text {vão }}}, \mathrm{f}_{\text {lim }}-$ flecha limite, em cm;

$\mathrm{I}$ - comprimento da viga, em $\mathrm{cm}$.

\subsection{ESTUDO DO ESPAÇO DE BUSCA}

O objetivo do processo de otimização estrutural desejado é a redução do volume da peça, buscando maior esbeltez e menor peso. A fim de conhecer o espaço de busca para posterior aplicação do procedimento de otimização no programa computacional Ansys, análises foram executadas a fim de visualizar a interferência das variáveis entre si. As restrições laterais foram impostas para os valores do parâmetro " $\mathrm{k}$ ", sendo $1,993 \leq k \leq 2,507$ para o domínio 3 e armadura simples, para os valores da flecha $f_{t}, 0 \leq f_{t} \leq f_{\text {lim }}=1,6$ $\mathrm{cm}$, e também para os valores da armadura efetiva, $A s_{\text {min }} \leq A s_{\text {ef }} \leq A s_{\text {máx. }}$. Estas são as variáveis de estado do procedimento de otimização.
Para valores fixos do carregamento (q) $(0,8 \mathrm{kN} / \mathrm{cm})$, do comprimento da viga (/) de $400 \mathrm{~cm}$ e, o diâmetro das barras longitudinais, levando-se

em conta a limitação do espaço de busca com as restrições laterais, tem-se os valores apresentados na Tabela 1, para diferentes valores da largura (b) e altura da viga (h) da viga, que são as variáveis de projeto do problema. A única restrição necessariamente imposta para estas variáveis é a dimensão mínima para a largura da viga, " $b_{\text {min }}$.

A partir dos valores obtidos, relacionouse os diferentes valores da altura " $h$ " $(\mathrm{cm})$ e da largura " $\mathrm{b}$ " $(\mathrm{cm})$ da viga de concreto armado para a plotagem dos gráficos representados na Figura 2. A região com contorno em linhas pretas facilita a visualização dos valores que atendem às restrições de projeto.

A Figura 3 apresenta a relação entre a variação da altura da viga (h) e a armadura efetiva (As,ef), mostrando que quanto maior a altura da viga menor a área de aço exigida, o que é de se esperar. O número " $n$ " representa o número de barras. A Figura 4 mostra os valores de volumes para diferentes dimensões de altura (h) e largura (b) da viga de concreto armado.

\begin{tabular}{ccccccccccc}
\hline \multicolumn{10}{c}{ TABELA 1: Análise do espaço de busca. } \\
$\begin{array}{ccccccccccc}\mathrm{bmin} \\
(\mathrm{cm})\end{array}$ & $\begin{array}{c}\mathrm{b} \\
(\mathrm{cm})\end{array}$ & $\begin{array}{c}\mathrm{h} \\
(\mathrm{cm})\end{array}$ & $\begin{array}{c}\mathrm{q} \\
(\mathrm{kN} / \mathrm{cm})\end{array}$ & $\begin{array}{c}\text { Msd } \\
(\mathrm{kNcm})\end{array}$ & $\mathrm{k}$ & $\mathrm{n}$ & $\begin{array}{c}\text { Asef } \\
\left(\mathrm{cm}^{2}\right)\end{array}$ & Mr $(\mathrm{kNcm})$ & $\begin{array}{c}\mathrm{ft} \\
(\mathrm{cm})\end{array}$ & volume $\left(\mathrm{cm}^{3}\right)$ \\
\hline 28 & 30 & 40 & 0,8 & 23240 & 1,8934 & 6 & 18,8495 & 4278,0309 & 2,05 & 480000 \\
\hline 28 & 35 & 40 & 0,8 & 23380 & 2,0390 & 6 & 18,8495 & 4839,2114 & 2,01 & 560000 \\
\hline 28 & 40 & 40 & 0,8 & 23520 & 2,1733 & 6 & 18,8495 & 5407,8449 & 1,95 & 640000 \\
\hline 24 & 25 & 50 & 0,8 & 23275 & 2,2069 & 5 & 15,7080 & 5359,0416 & 1,58 & 500000 \\
\hline 24 & 30 & 50 & 0,8 & 23450 & 2,4085 & 5 & 15,7080 & 6252,9429 & 1,49 & 600000 \\
\hline 24 & 40 & 50 & 0,8 & 23800 & 2,7606 & 5 & 15,7080 & 8053,8607 & 1,26 & 800000 \\
\hline 20 & 20 & 60 & 0,8 & 23240 & 2,4048 & 4 & 12,5663 & 6056,4792 & 1,27 & 480000 \\
\hline 20 & 30 & 60 & 0,8 & 23660 & 2,9190 & 4 & 12,5663 & 8649,0966 & 0,97 & 720000 \\
\hline 16 & 16 & 70 & 0,8 & 23184 & 2,5381 & 3 & 9,4248 & 6499,8275 & 1,06 & 448000 \\
\hline 16 & 20 & 70 & 0,8 & 23380 & 2,8257 & 3 & 9,4248 & 7911,0898 & 0,91 & 560000 \\
\hline
\end{tabular}




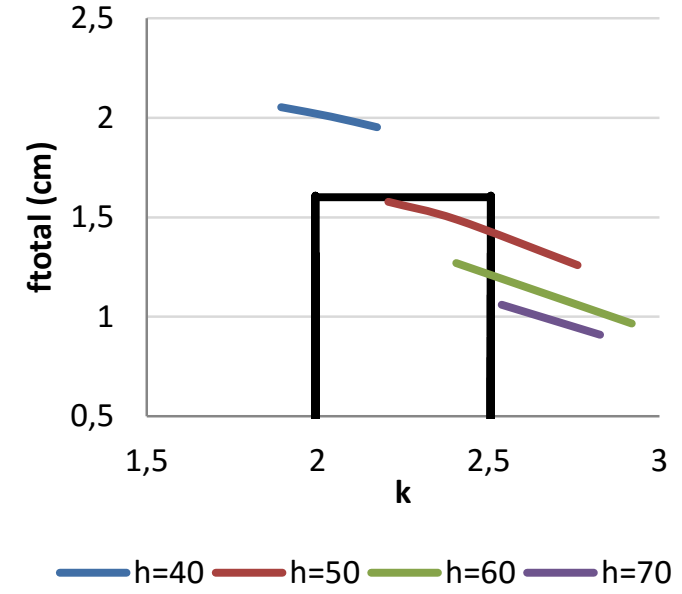

[a] Curvas com valores de $\boldsymbol{h}$ fixados e $\boldsymbol{b}$ variando.

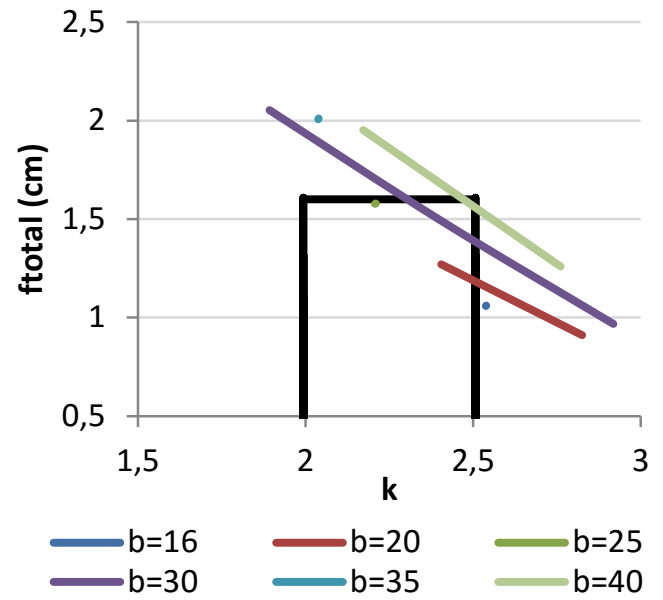

[b] Curvas com valores de $\boldsymbol{b}$ fixados e $\boldsymbol{h}$ variando.

FIGURA 2: Valores de $h$ e $b(\mathrm{~cm})$ que respeitam as restrições.

FONTE: Autoria própria.

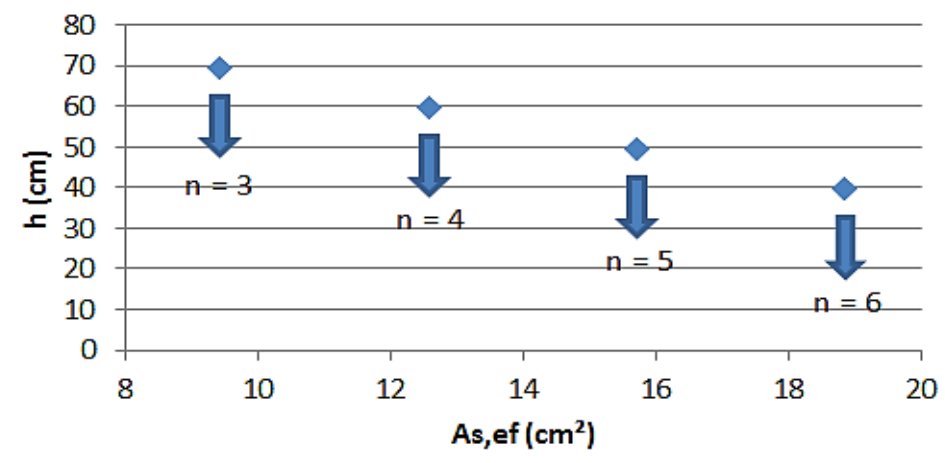

FIGURA 3: Altura da viga $(h) x$ área de aço efetiva (As,ef).

FONTE: Autoria própria.

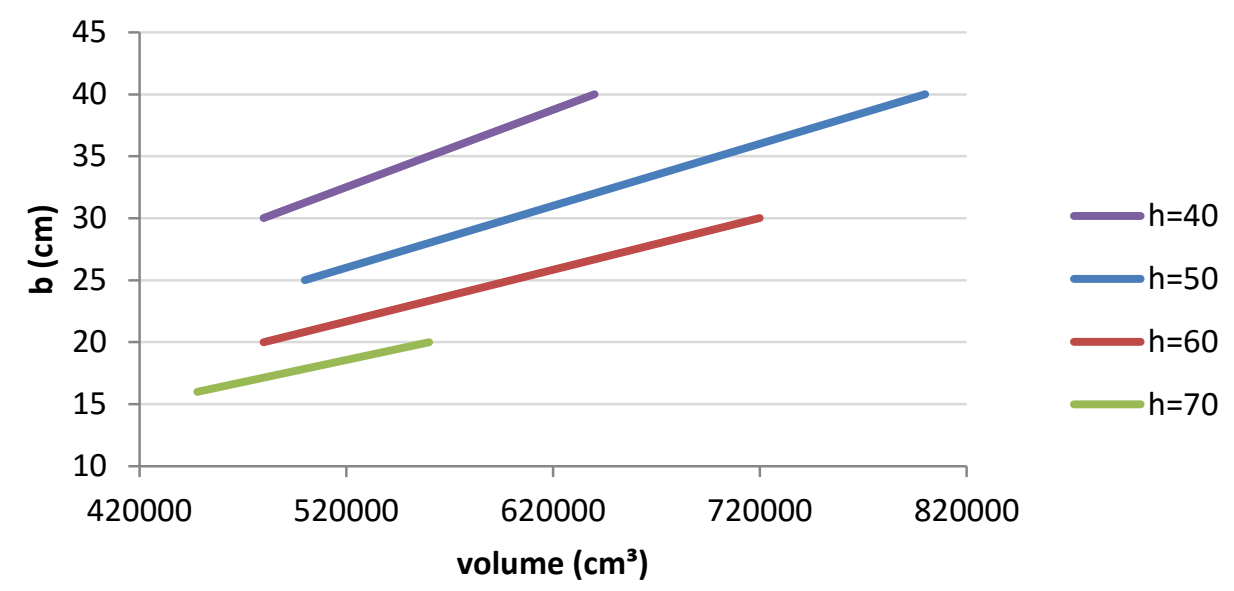

FIGURA 4: Valores de volumes de vigas com diferentes seções transversais.

FONTE: Autoria própria.

Para efeito de comparação, também foi realizado um novo dimensionamento adotando o diâmetro das barras longitudinais de $16 \mathrm{~mm}$, mostrado na Figura 5. Pode-se observar que houve uma pequena diminuição na área efetiva (As,ef) a ser utilizado para as mesmas solicitações. Porém, há um aumento na largura da seção, já que o número de barras aumenta e, consequentemente, o número de espaçamentos, por conta da menor área da seção transversal de cada barra de aço. 


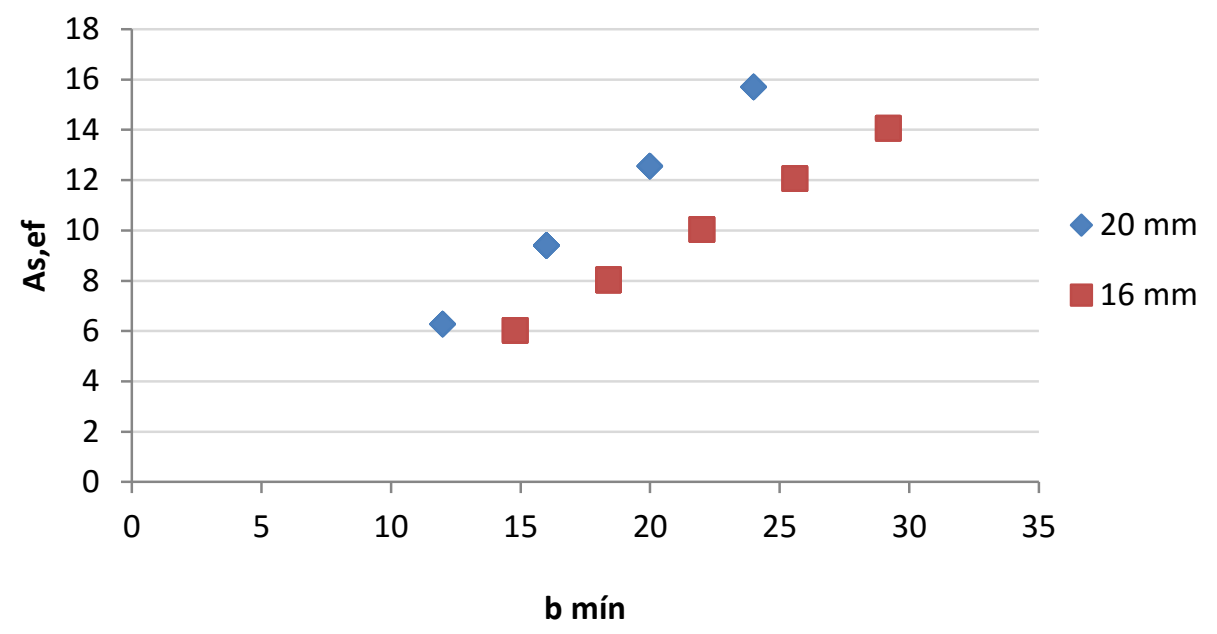

FIGURA 5: Análise de diferentes diâmetros para as barras longitudinais.

FONTE: Autoria própria.

\subsection{DADOS DE ENTRADA NO MÓDULO DE OTIMIZAÇÃO DO ANSYS}

Os conjuntos inviáveis são aqueles gerados a partir de valores de variáveis de projeto (largura e altura da seção transversal) que se encontram dentro do espaço de busca mas que seus resultados não respeitam as restrições impostas no módulo de otimização, seja para área de armadura, flecha ou o coeficiente " $k$ ". No módulo de otimização do Ansys alguns valores e características são escolhidos pelo usuário na implantação de cada método ou ferramenta a serem utilizados.

$\mathrm{Na}$ aplicação do método Subproblema, os valores e características definidos pelo usuário são o número máximo de iterações, aqui fixado como 40, e número máximo de conjuntos inviáveis, igual a 15. Ainda neste método, têm-se duas opções para curvas de ajuste para as funções das Variáveis de Estado e para a Função Objetivo, curvas de ajuste lineares ou quadráticas, ambas serão utilizadas e estudadas.

Para a execução do método de Primeira Ordem, o número de máximo de iterações também deve ser escolhido. O problema da viga de concreto armado não convergiu quando utilizou-se o método de primeira ordem, independentemente do número máximo de iterações inserido no programa, o que será detalhado posteriormente.

$\mathrm{Na}$ utilização da ferramenta Geração de Projeto Randômica os conjuntos viáveis são aqueles que respeitam as restrições impostas no módulo de otimização, como nos métodos. Os valores fixados para o controle da ferramenta de Geração Randômica de conjuntos são o número máximo de iterações, igual a 30, e número desejado de conjuntos viáveis, igual a 15.

No caso da utilização de Geração de Varredura deve-se escolher $o$ ponto de avaliação sobre o qual ela se desenvolverá. Este ponto será sempre definido como o melhor conjunto viável já encontrado anteriormente. O número de varreduras por variável de projeto definido pelo usuário deve ter seu valor fixado, como, por exemplo, neste estudo admitiu-se 10 .

\subsection{ANÁLISES DOS RESULTADOS DOS PROCEDIMENTOS DE OTIMIZAÇÃO PARA A VIGA DE CONCRETO ARMADO}

Com o objetivo de encontrar a melhor combinação de métodos e ferramentas disponíveis no procedimento de otimização no programa Ansys, foram realizadas as análises cujos resultados estão na Tabela 2. 
TABELA 2: Resultados das combinações da otimização para a viga de concreto armado.

\begin{tabular}{|c|c|c|c|c|c|c|c|c|}
\hline \multicolumn{2}{|c|}{ Combinação (SUBPROBLEMA) } & Projeto ótimo e esforço computacional & $\begin{array}{l}\text { Altura h } \\
(\mathrm{cm})\end{array}$ & $\begin{array}{l}\text { Largurab } \\
\text { (cm) }\end{array}$ & $\begin{array}{l}\text { Volume } \\
\left(\mathrm{cm}^{3}\right)\end{array}$ & Asef $\left(\mathrm{cm}^{2}\right)$ & k & $\begin{array}{c}\text { Flecha } \\
\text { total }(\mathrm{cm})\end{array}$ \\
\hline \multicolumn{2}{|c|}{$\mathrm{KFOBJ}=\mathrm{Q}+\mathrm{X} / \mathrm{KF5V}=\mathrm{Q}$} & $12^{2}$ projeto de 11 iterações $(7,5 \mathrm{~s})$ & 49,779 & 24,272 & 483290 & 15,708 & 2,1654 & 1,601 \\
\hline \multicolumn{2}{|c|}{$\mathrm{KFOBJ}=\mathrm{Q}+\mathrm{X} / \mathrm{KFSV}=\mathrm{L}$} & $19^{2}$ projeto de 18 iteraçốes $(9,65)$ & 49,786 & 24,258 & 483090 & 15,708 & 2,1652 & 1,6008 \\
\hline \multicolumn{2}{|c|}{$\mathrm{KFOBJ}=\mathrm{Q}+\mathrm{X} / \mathrm{KF} 5 \mathrm{~V}=\mathrm{Q}+\mathrm{X}$} & $12^{2}$ projeto de 11 iterações $(7,45)$ & 49,819 & 24,254 & 483310 & 15,708 & 2,1665 & 1,5999 \\
\hline \multicolumn{2}{|c|}{$\mathrm{KFOBJ}=\mathrm{L} / \mathrm{KF} 5 \mathrm{~V}=\mathrm{L}$} & $17^{\circ}$ projeto de 16 iteraçốes $(8,45)$ & 49,81 & 24,258 & 483310 & 15,708 & 2,1662 & 1,5998 \\
\hline \multicolumn{2}{|c|}{$\mathrm{KFOBJ}=\mathrm{L} / \mathrm{KFSV}=\mathrm{Q}$} & $11^{2}$ projeto de 10 iterações $(8,35)$ & 49,846 & 24,258 & 483670 & 15,708 & 2,168 & 1,5981 \\
\hline \multicolumn{2}{|c|}{$\mathrm{KFOBJ}=\mathrm{L} / \mathrm{KFSV}=\mathrm{Q}+\mathrm{X}$} & $11^{2}$ projeto de 10 iteraçốes $(8,65)$ & 49,806 & 24,257 & 483260 & 15,708 & 2,1661 & 1,5999 \\
\hline \multicolumn{2}{|c|}{$\mathrm{KFOBJ}=\mathrm{Q} / \mathrm{KF5V}=\mathrm{L}$} & $19^{2}$ projeto de 18 iteraçốes (13,3 s) & 49,79 & 24,259 & 483140 & 15,708 & 2,1654 & 1,6007 \\
\hline \multicolumn{2}{|c|}{$\mathrm{KFOBJ}=\mathrm{Q} / \mathrm{KFSV}=\mathrm{Q}$} & $12^{2}$ projeto de 11 iterações $(13,15)$ & 49,782 & 24,272 & 483320 & 15,708 & 2,1656 & 1,6008 \\
\hline \multicolumn{2}{|c|}{$\mathrm{KFOBJ}=\mathrm{Q} / \mathrm{KF5V}=\mathrm{Q}+\mathrm{X}$} & $12^{\circ}$ projeto de 11 ite raçốes (115) & 49,839 & 24,254 & 483510 & 15,708 & 2,1674 & 1,5985 \\
\hline \multirow{2}{*}{$\begin{array}{l}\text { Randômica + Subproblema } \\
\qquad(\mathrm{KFOBJ}=\mathrm{L} / \mathrm{KFSV}=\mathrm{L})\end{array}$} & Randômic & $1^{\circ}$ proje to de 30 iteraç̃̃es - proj eto inicial $(15,25)$ & 50 & 30 & 600000 & 15,708 & 2,4085 & 1,488 \\
\hline & Subproblema $(\mathrm{KFOB} \mathrm{J}=\mathrm{L} / \mathrm{KFSV}=\mathrm{L})$ & $\begin{array}{c}8^{2} \text { projeto de } 7 \text { iteraçõ̃es }(3,25) \\
\text { (depois de 30ite raçõ̃es da ferramenta) }\end{array}$ & 49,849 & 24,258 & 483700 & 15,708 & 2,1681 & 1,5979 \\
\hline \multirow{2}{*}{$\begin{array}{l}\text { Randômica + 5ubproblema } \\
(\text { KFOBJ }=\mathrm{Q}+\mathrm{X} / \mathrm{KFSV}=\mathrm{Q})\end{array}$} & Randômica & $1^{\circ}$ proje to de 30 iteraç̃es - proj eto inicial $(14,9 \mathrm{~s})$ & 50 & 30 & 600000 & 15,708 & 2,4085 & 1,488 \\
\hline & Subproblema $(\mathrm{KFOBJ}=\mathrm{Q}+\mathrm{X} / \mathrm{KFSV}=\mathrm{Q})$ & $\begin{array}{c}8^{2} \text { projeto de 7ite rações (3,3 s) } \\
\text { (depois de 30iterações da ferramenta) }\end{array}$ & 49,887 & 24,255 & 483990 & 15,708 & 2,1697 & 1,5962 \\
\hline \multirow{2}{*}{$\begin{array}{l}\text { Randômica + 5ubproblema } \\
(\text { KFOBJ }=\mathrm{Q}+\mathrm{X} / \mathrm{KFSV}=\mathrm{L})\end{array}$} & Randômic & $1^{\circ}$ proje to de 30 iteraç̃es - proj eto inicial $(14,5 \mathrm{~s})$ & 50 & 30 & 600000 & 15,708 & 2,4085 & 1,488 \\
\hline & Subproblema $($ KFOBJ $=Q+X / K F 5 V=L)$ & $\begin{array}{c}8^{\circ} \text { projeto de } 7 \text { ite raçõ̃es }(3,6 \mathrm{~s}) \\
\text { (depois de 30ite raçốes da ferramenta) }\end{array}$ & 49,849 & 24,258 & 483690 & 15,708 & 2,1681 & 1,5979 \\
\hline \multirow{3}{*}{$\begin{array}{c}\text { Randômica + } 5 \text { ubproblema + } \\
\text { Varredura } \\
\text { (KFOBJ }=\mathrm{L} / \text { KFSV }=\mathrm{L} \text { ) }\end{array}$} & Randômica & $1^{2}$ proje to de 30 iteraç̃es - proj eto inicial $(15,25)$ & 50 & 30 & 600000 & 15,708 & 2,4085 & 1,488 \\
\hline & Subproblema $(\mathrm{KFOBJ}=\mathrm{L} / \mathrm{KFSV}=\mathrm{L})$ & $\begin{array}{c}8^{2} \text { projeto de } 7 \text { ite raçõ̃es }(3,25) \\
\text { (depois de 30ite raçốes da ferramenta) }\end{array}$ & 49,849 & 24,258 & 483700 & 15,708 & 2,1681 & 1,5979 \\
\hline & Varredura & $\begin{array}{l}\text { executou mais } 20 \text { iteraçốes, mas o proje to ótimo } \\
\text { foi mantido o anterior (do método) }\end{array}$ & 49,849 & 24,258 & 483700 & 15,708 & 2,1681 & 1,5979 \\
\hline \multirow{3}{*}{$\begin{array}{c}\text { Randômica + 5ubproblema + } \\
\text { Varredura } \\
(\mathrm{KFOBJ}=\mathrm{Q}+\mathrm{X} / \mathrm{KFSV}=\mathrm{Q})\end{array}$} & Randômica & $1^{\circ}$ proje to de 30 iteraç̃es - proj eto inicial $(14,95)$ & 50 & 30 & 600000 & 15,708 & 2,4085 & 1,488 \\
\hline & Subproblema $(\mathrm{KFOBJ}=\mathrm{Q}+\mathrm{X} / \mathrm{KFSV}=\mathrm{Q})$ & $\begin{array}{c}8^{\circ} \text { projeto de 7iteraçõ̃es (3,35) } \\
\text { (depois de 30iterações da ferramenta) }\end{array}$ & 49,887 & 24,255 & 483990 & 15,708 & 2,1697 & 1,5962 \\
\hline & Varredura & $\begin{array}{l}11^{\circ} \text { projeto de } 20 \text { iterações }(7,15) \\
\text { (depois de } 38 \text { iteraçốes anteriores) }\end{array}$ & 49,887 & 24 & 478910 & 15,708 & 2,1587 & 1,6004 \\
\hline \multirow{3}{*}{$\begin{array}{c}\text { Randômica + 5ubproblema + } \\
\text { Varredura } \\
(\text { KFOBJ }=\mathrm{Q}+\mathrm{X} / \mathrm{KFSV}=\mathrm{L})\end{array}$} & Randômic & $1^{\circ}$ proje to de 30 iteraç̃es - proj eto inidal $(14,5 \mathrm{~s})$ & 50 & 30 & 600000 & 15,708 & 2,4085 & 1,488 \\
\hline & Subproblema (KFOBJ $=\mathrm{Q}+\mathrm{X} / \mathrm{KF5V}=\mathrm{L})$ & $\begin{array}{c}8^{2} \text { projeto de } 7 \text { iteraçốes }(3,65) \\
\text { (depois de 30iteraçốes da ferramenta) }\end{array}$ & 49,849 & 24,258 & 483690 & 15,708 & 2,1681 & 1,5979 \\
\hline & Varredura & $\begin{array}{l}\text { executou mais } 20 \text { iteraçôes, mas o proje to ótimo } \\
\text { foi mantido o anterior (do método) }\end{array}$ & 49,849 & 24,258 & 483700 & 15,708 & 2,1681 & 1,5979 \\
\hline
\end{tabular}

LEGENDA: $L=$ linear; $Q$ = quadrática; $Q+X=$ quadrática mais termox; KFOBJ = aurva de ajuste para função objetivo; KFSV = curva de ajuste para variáveis de estado.

FONTE: Autoria própria.

Em muitos casos, os resultados gerados pelos métodos de Aproximação por Subproblema e de Primeira Ordem são muito parecidos. Vale lembrar que o método de ordem zero exige menor esforço computacional enquanto que o método geralmente mais preciso é o que utiliza informação da primeira derivada. Entretanto, quando se utilizou o método de Primeira Ordem o procedimento de otimização os resultados não convergiram.

A melhor combinação para o problema, isto é, a combinação de ferramentas e métodos de otimização que resultou na melhor solução, menor volume, foi dada pela sequência Geração de Projeto de Randômica + Subproblema (KFOBJ = Q+X / KFSV $=\mathrm{Q})+$ Geração de Varredura. Com um volume de
$478.910 \mathrm{~cm}^{3}$, a largura de $24 \mathrm{~cm}$ e a altura de $49,887 \mathrm{~cm}$ a solução resultou em 5 barras longitudinais de diâmetro de $20 \mathrm{~mm}$, que correspondem a área transversal de $15,708 \mathrm{~cm}^{2}$. A Figura 6 obtida no programa Ansys permite observar as tentativas de convergência para variações de "b" e " $h$ ", "k" e " $\mathrm{ft}$ ", e volume, respectivamente.

A aplicação da ferramenta Geração de Projeto Randômica anteriormente ao método é melhor justificável pelo fato de encontrar valores de altura e largura iniciais mais adequados para a sequência do procedimento. Esta busca valores aleatórios para as variáveis de projeto em todo o espaço de busca, abrindo um leque maior de possibilidades de encontrar um melhor ponto de 
partida. Porém, seus resultados dependem da quantidade de iterações especificado pelo usuário em relação ao tamanho do espaço de busca (limites superiores e inferiores definidos para as variáveis de projeto), além de ser influenciada também pelos valores iniciais escolhidos destas variáveis.

A

Tabela 3 relaciona, somente para a ferramenta Randômica, diferentes resultados aos dados e espaços de busca definidos inicialmente, com o número de iterações fixados e igual a 30.

Com os conhecimentos já obtidos acerca da ferramenta de Geração de Varredura e, também, analisando os resultados da Tabela 2, é perfeitamente possível afirmar que uma boa utilização desta seria ao final do procedimento de otimização, onde os valores das variáveis de projeto se encontram muito próximos ou já constituem o conjunto ótimo. Desta forma, ao fixar um dos valores, já considerado ótimo, e promover a varredura do espaço de busca alterando o valor da outra variável, pode-se encontrar um conjunto de projeto ainda melhor do que o atual.

\section{CONSIDERAÇÕES FINAIS}

O estudo desenvolvido permitiu um melhor entendimento dos métodos e ferramentas de otimização disponíveis numericamente do programa computacional Ansys, para aplicação adequada em problemas de minimização do volume de vigas de concreto armado.

Finalmente, as principais conclusões obtidas neste estudo podem ser agrupadas como segue:

- Com relação aos métodos de otimização, foi visto que deve-se utilizar aquele que melhor se adequa a cada caso. Desta forma, para o problema da viga de concreto armado o método de Subproblema se mostrou melhor, visto que o Primeira Ordem não gerou soluções convergidas;

- Quanto às ferramentas de otimização, observou-se que a combinação "Geração de Projeto Randômica + Método + Geração de varredura" foi muito eficiente devido às características de cada uma dessas

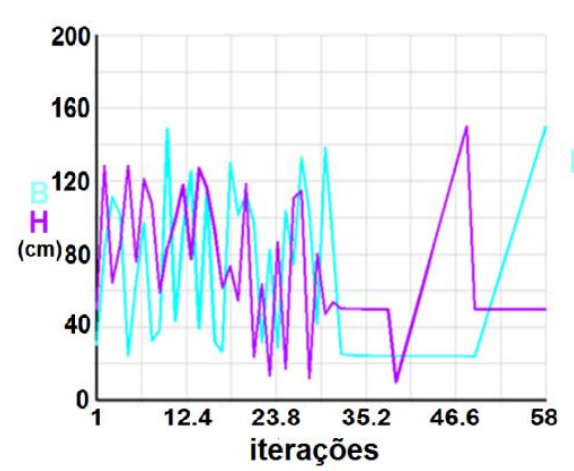

[a] Altura $(h)$ e largura $(b)$ x número de iterações.

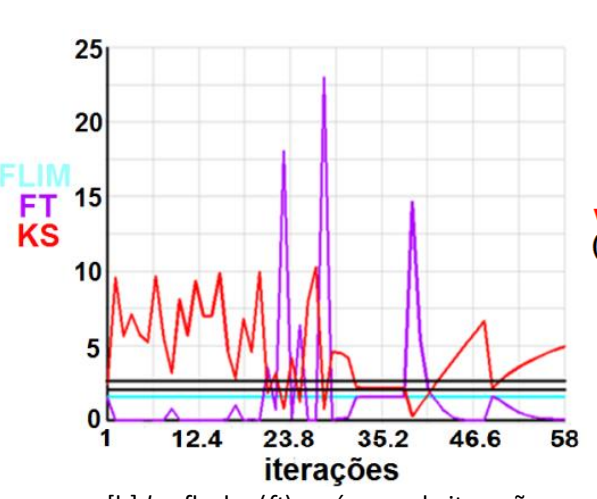

[b] $k$ e flecha $(f t)$ x número de iterações.

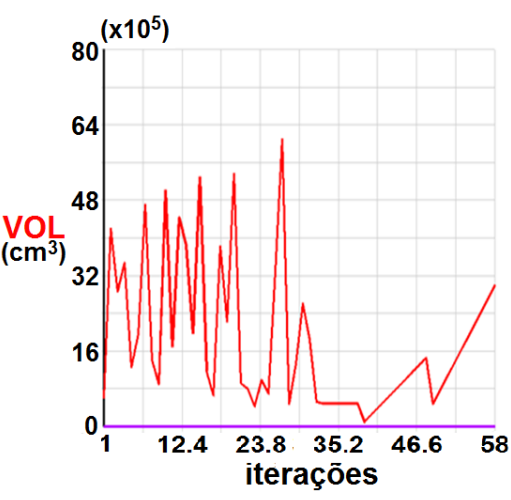

[c] Volume x número de iterações.

FIGURA 6: Resultados gráficos do programa computacional.

FONTE: Autoria própria.

TABELA 3: Resultados dos testes feitos com a ferramenta de Geração de Projeto Randômica.

\begin{tabular}{|c|c|c|c|c|c|c|c|}
\hline Dados iniciais & Projeto ótimo e esforço computacional & $\begin{array}{l}\text { Altura h } \\
(\mathrm{cm})\end{array}$ & $\begin{array}{l}\text { Largura b } \\
(\mathrm{cm})\end{array}$ & $\begin{array}{c}\text { Volume } \\
\left(\mathrm{cm}^{3}\right)\end{array}$ & Asef $\left(\mathrm{cm}^{2}\right)$ & k & $\begin{array}{c}\text { Flecha total } \\
(\mathrm{cm})\end{array}$ \\
\hline $\begin{array}{c}h=50 \mathrm{~cm}, \text { sendo } 10<\mathrm{h}<150 \\
\mathrm{~b}=30 \mathrm{~cm} \text {, sendo } \mathrm{bmin}<\mathrm{b}<150\end{array}$ & $\begin{array}{l}1^{\circ} \text { projeto de } 30 \text { iterações - projeto inicial } \\
\qquad(14,5 \mathrm{~s})\end{array}$ & 50 & 30 & 600000 & 15,708 & 2,4085 & 1,488 \\
\hline $\begin{array}{c}\mathrm{h}=50 \mathrm{~cm} \text {, sendo } 30<\mathrm{h}<60 \\
\mathrm{~b}=30 \mathrm{~cm} \text {, sendo } \mathrm{bmín}<\mathrm{b}<40\end{array}$ & $8^{\circ}$ projeto de 30 iterações $(13,9 \mathrm{~s})$ & 50,854 & 25,12 & 510990 & 15,708 & 2,2523 & 1,5365 \\
\hline $\begin{array}{c}\mathrm{h}=40 \mathrm{~cm} \text {, sendo } 10<\mathrm{h}<150 \\
\mathrm{~b}=40 \mathrm{~cm} \text {, sendo } \mathrm{bmin}<\mathrm{b}<150\end{array}$ & $\begin{array}{c}1^{\circ} \text { projeto de } 30 \text { iterações - projeto inicial } \\
(14,6 \mathrm{~s}) \text { (inviável) }\end{array}$ & 40 & 40 & 640000 & 18,85 & 2,1733 & 1,9524 \\
\hline $\begin{array}{c}\mathrm{h}=40 \mathrm{~cm} \text {, sendo } 30<\mathrm{h}<60 \\
\mathrm{~b}=40 \mathrm{~cm} \text {, sendo } \mathrm{bmín}<\mathrm{b}<40\end{array}$ & $11^{\circ}$ projeto de 30 iterações $(13,7 \mathrm{~s})$ & 48,95 & 29,811 & 583700 & 15,708 & 2,3475 & 1,5475 \\
\hline $\begin{array}{c}\text { Randômica + Subproblema + } \\
\text { Varredura } \\
\text { (KFOBJ = Q+X / KFSV = Q) }\end{array}$ & $\begin{array}{l}\text { Utilizando o melhor processo com a } \\
\text { ferramenta randômica, o segundo. }\end{array}$ & 49,916 & 24 & 479190 & 15,708 & 2,16 & 1,5991 \\
\hline
\end{tabular}


ferramentas. Porém, ainda assim é importante analisar resultados de outras combinações, levando-se em conta a possibilidade de convergência em um mínimo local, obtendo soluções incorretas, pois deseja-se o mínimo global;

- Na maioria dos problemas, a aplicação dos métodos de otimização, sem a utilização das ferramentas, gera resultados próximos aos ótimos, e a aplicação destas justificam-se apenas na maior precisão do resultado. No problema aqui estudado, as soluções sem a utilização das ferramentas de otimização geraram resultados muito satisfatórios. Pequenas imprecisões no valor do volume podem ser desprezadas, visto que as variações de dimensões da seção transversal em poucos milímetros, na prática não é adequada em seções transversais em peças de concreto armado;

- Quanto aos resultados obtidos para a viga de seção retangular de concreto, o melhor resultado foi encontrado com a combinação "Geração de Projeto Randômica + Subproblema $($ KFOBJ $=\mathrm{Q}+\mathrm{X} / \mathrm{KFSV}=\mathrm{Q})+$ Geração de Varredura" atendendo a flecha limite de 1,6 cm, com 5 barras para a armadura longitudinal de diâmetro de $20 \mathrm{~mm}$, dimensionada no domínio 3, obedecendo as restrições impostas para o parâmetro k. Ao aplicar a ferramenta Geração de Projeto Randômica deve-se ter cuidado com os dados de entrada, as dimensões iniciais, o número de iterações desejadas e o tamanho do espaço de busca.

Como sugestões para trabalhos futuros, pode-se acrescentar novas variáveis de estado, como o $f_{c k}$ do concreto ou ainda diâmetros diferentes para as barras longitudinais que é uma variável discreta. Existem seções transversais muito interessantes a serem estudadas como continuidade ao trabalho que analisou somente seções retangulares. Também, há outros tipos de análises importantes para a peça estrutural que enriqueceria bastante o estudo, como o dimensionamento da viga de concreto armado para as tensões de cisalhamento, a verificação de abertura de fissuras, que é de grande importância e obrigatória segundo as normas brasileiras vigentes.

Vale ressaltar que a otimização da geometria da seção transversal é de extrema importância para a aplicação de vigas de concreto pré-moldado, onde o peso durante as fases transitórias é um fator que implica diretamente nos custos e nas facilidades de manuseio.

\section{AGRADECIMENTOS}

Agradecemos ao CNPq pela bolsa de estudos concedida para o desenvolvimento deste projeto de iniciação científica.

\section{REFERÊNCIAS BIBLIOGRÁFICAS}

ASSOCIAÇÃO BRASILEIRA DE NORMAS TÉCNICAS, NBR 6118:2014: Projeto de Estruturas de Concreto. Rio de Janeiro, 2014.

ASSOCIAÇÃO BRASILEIRA DE NORMAS TÉCNICAS, NBR 8681:2003: Ações e segurança nas estruturas. Rio de Janeiro, 2003

ANSYS MANUAL, HELP SYSTEM. Advanced Analysis Techniques Guide - Design Optimization. ANSYS, Inc., USA, 2009.

ÁVILA, S. L. Algoritmos genéticos aplicados na otimização de antenas refletoras. Dissertação (Mestrado). Universidade Federal de Santa Catarina, Programa de Pós-graduação em Engenharia Elétrica, 2002.

CASTILHO, V. C. Otimização de componentes de concreto pré-moldado protendidos mediante algoritmos genéticos. Tese (Doutorado). Escola de Engenharia de São Carlos, Universidade de São Paulo, 2003.

COOK, R. D.; MALKUS, D. S.; PLESHA, M. E. Concepts and applications of finite element analysis. New York: John Wiley \& Sons, 1989.

COSTA, R. R. R. Otimização do Comportamento de Sistemas Estruturais Pré-Moldados de Concreto com Ligações Viga-Pilar Deformáveis à Flexão. Dissertação (Mestrado). Faculdade de Engenharia Civil, Universidade Federal de Uberlândia, 2015

COSTA, R. R. R.; LIMA, M. C. V.; ALVA, G. M. S. Minimização da rigidez à flexão de ligações viga-pilar em sistemas estruturais pré-moldados de concreto. Ciência \& Engenharia, v.24, p.53-62, 2015. 
HUEBNER, K. H.; THORNTON, E. A. The finite element method for engineers. New York: John Wiley \& Sons, 1982.

KIM, N. H. Design optimization. The CRC Handbook of Mechanical Engineering, 2003.

MACAMBIRA, E. M. Otimização combinatória e algoritmos. Universidade Federal da Paraíba. Disponível em: <http://www.de.ufpb.br/ elder/>. Acesso em janeiro de 2015.

MARINHO, I. J. P. Projeto ótimo de estruturas metálicas de arquibancadas reutilizáveis via Ansys. Dissertação (Mestrado). Pontifícia Universidade Católica do Rio de Janeiro, Rio de Janeiro, 2002.

SORIANO, H. L. Método de elementos finitos em análise de estruturas. São Paulo: EDUSP, 2003.

TORRES, J. v. S. Otimização de pórticos de concreto armado utilizando o sistema computacional Ansys. Dissertação (Mestrado). Universidade Federal de Pernambuco. CTG. Engenharia Civil, Recife, 2001. 